\title{
A Prevention and Automation of Public Distribution System using RFID and Facial Recognition Camera
}

\author{
Mr. P. Karthik ${ }^{\# 1,}$ S. Deepika ${ }^{\# 2}$, N. Haritha ${ }^{\# 3}$, S. Punitha ${ }^{\# 4}$ \\ $(A P / E C E)^{1}$ Dept. Of Electronics and Communication Engg. SNS College of Engineering Coimbatore, India \\ ${ }^{234}$ Dept. Of Electronics and Communication Engg. SNS College of Engineering Coimbatore, India
}

\begin{abstract}
Our Indian public distribution system involves corruption and this is due to the involvement of manual work. Though the government is providing an AADHAR number for authentication, there also occurs some chance in the corruption of goods so in this paper we are providing an RFID card. This card is to identify that, only the card holder is using this card, facial recognition is also used. When the person enters the shop holding a card the camera recognize the image of the person in the database of the PC. If the image matches the required goods are delivered. A database is maintained to know the quantity of goods sold and are remaining in the stack. This information is send to the government via GSM. Amount of goods to be distributed are displayed on the LCD display.
\end{abstract}

Keywords: - Rfid Reader, Gsm, Facial Recognition, At Commands.

\section{INTRODUCTION}

The present Public Distribution System (PDS) in India involves corruption and smuggling of goods because it involves manual work in each and every aspect. To eliminate this the government is providing a special number called "AADHAR" number which consists of information such as contact number, bank account information of people who reside in India. Even though using this number still corruption occurs, to eliminate this RFID card and facial recognition camera are used. When a person enters the shop, whose image is captured by the facial recognition camera and the captured image send to the computer where a database about the people using the card is maintained. It also consists of goods detail which is sold and the remaining goods in the shop. This information is sent to the government through GSM.

When the RFID card is shown the card owner details are verified in the database and it allows for further process. If the card details do not match with the image captured by the camera they cannot able to buy the products. The controlling process is fully maintained by the micro controller, which provides automatic solid and liquid pouring by a time specification. The product quantities are entered after swiping the card. The amount of goods to be delivered is based on time fixed for each goods. The government will allot the amount of goods to be supplied to every family which reside in India. Separate pouring methods are adopted to deliver the goods.

\section{COMPONENT OF AUTOMATED SYSTEM}

As the name implies the automation is done using facial recognition, RFID and micro controller. The automation of the system is divided into two types:

- Hardware

- Software

The hardware includes into three parts:

- Facial recognition camera interfacing with a PC: The facial recognition camera captures the image and sends it to the PC where a separate database is maintained.

- The RFID card reader interfacing with micro controller and PC: The RFID based smart card reader is connected to micro controller and a PC via RS232.

- Micro controller and PC: The micro controller and the PC are connected so that the information from the PC it controls the hardware system.

- GSM module interfacing with micro controller: Here the GSM module is used to exchange the information in the form of SMS between micro controller assembly and government database. This exchange of information is required for user authentication and for other details.

The software includes:

- The RFID card reader sends the command to when there is RFID card detected.

- When the micro controller receives the command from RFID card readers, it sends commands to GSM module to send messages to the government database. 
- The message consists of a quantity of goods details about the card holder. The main part of the software is the GSM module.

All these are happening only when the person holding the RFID card enters the shop, his face recognizes the facial recognition camera which is connected to a $\mathrm{PC}$ which has the details of their requirements.

It matches the image, if the image captured by the camera matches the image in the database when the RFID card is shown. If the image does not match one could not get the goods. Thus the rationing goods are prevented from those who are trying to purchase the goods illegally.

\section{BLOCK DIAGRAM}

\section{BLOCK DIAGRAM AND SPECIFICATION}

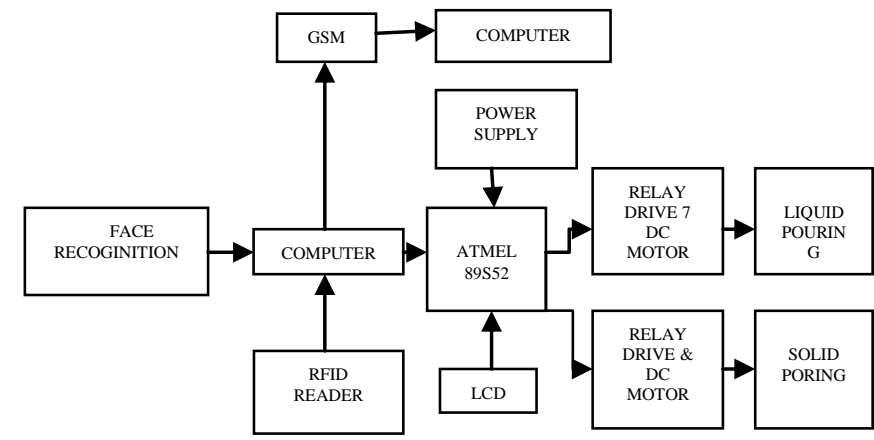

\section{BLOCK SPECIFICATIONS}

- $\quad$ FACIAL RECOGNITION CAMERA: It is a computer application for automatically identifying or verifying features from an image of the person from a digital image or a video frame from a video source. One of the ways to do this is by comparing selected facial features from the image and a facial database. Some facial recognition algorithms identify facial features by extracting features from an image of the subject's face. For example, an algorithm may analyze the relative position, size, and shape of the eyes, nose, cheekbones, and jaw. The facial recognition camera is used to capture the image when a person enters a shop it compares the image which is present in the database. It is used for the authentication process. Then the person is allowed to scratch the RFID card. To deliver the goods the image should be matched with the smart card.

- $\quad$ RFID READER: RFID reader is a device which is used to communicate with RFID tags by receiving and transmitting signals. These signals use radio waves for wireless communication. The identification is done through a unique serial number. It is a block which is used to detect the RFID TAG when the user shows the RFID card. It sends the number to the

- $\quad$ Micro controller module for further processing.

- The RFID READER used to have the following specification:

\begin{tabular}{|l|l|}
\hline Parameters & Value \\
\hline Input voltage & 9 to 15v AC/DC \\
\hline Data speed (Output) & $9600 \mathrm{bps}$ \\
& 8 bit data \\
\hline Signal level (Output) & Level defined by RS232 \\
\hline Detection range & 25 to 30cm \\
\hline Tag indication & By LED and Buzzer \\
\hline
\end{tabular}

- $\quad$ RS232: The RFID reader works at different mode and the micro controller works at different mode. So the RFID reader and the micro controller cannot be connected directly. The drivers provide RS232 voltage level outputs (approximately $\pm 7.5 \mathrm{v}$ ) from a single $+5 \mathrm{v}$ supply via on chip charge pumps and external capacitors. This makes it useful for implementing RS232 in devices that otherwise do not need any voltages outside the $0 \mathrm{v}$ to $+5 \mathrm{v}$ range, as power supply design does not need to be made more complicated just for driving the RS232 in this case. 
To connect these two devices a special wire is used, it is called RS232. This module provides the required interface between RFID.

- GSM MODULE: It is a network which is made up of multiple components and interfaces that facilitate sending and receiving of signals. It is the block which serves in order to exchange of information between micro controller and government database. Here GSM is used for message service. The message consists of details, such as the quantity of goods which are available in the shop, who purchased the goods and types of goods that are available in the shop. The GSM MODULE used having following specification:

\begin{tabular}{|l|l|}
\hline Parameters & Value \\
\hline A data rate & 9600 baud CSD \\
\hline Service support & $\begin{array}{l}\text { GSM data transmission, } \\
\text { SMS }\end{array}$ \\
\hline Status indicator & 1 LED, Alarm \\
\hline Antenna impedance & 50ohms \\
\hline Digital I/O output & $\begin{array}{l}8 \text { TTL Outputs, 8 TTL } \\
\text { Inputs. }\end{array}$ \\
\hline Operating temperature range & Operating temperature range \\
\hline
\end{tabular}

RELAY DRIVE: It is an electrically operated switch. Many relays use an electromagnet to operate a switching mechanism, but other operating principles are also used. Relays find applications where it is necessary to control a circuit by a low power signal or where several circuits must be controlled by one signal. The first relay was used in long distance telegraph circuits, repeating the signal coming from one circuit and re-transmitting it to another. Relays found extensive use in telephone exchanges and early computers to perform logical operations. A type of relay that can handle the high power required to directly drive an electric motor is called a conductor. Solid state relays to perform switching. Relays with calibrated operating characteristics and sometimes multiple operating coils are used to protect electrical circuits from overload or faults in the modern electric power system. These functions are performed by digital instruments still called "protection relays".

It consist of a coil of wire surrounding a soft iron core, an iron yoke, which provides a low reluctance path for magnetic flux, a movable iron armature and a set or set of contacts. The armature is hinged to the yoke and mechanically linked to a moving contact, it is held in place by a spring so that when the relay is de-energized there is an air gap in the magnetic circuit. In this condition, one of the two sets of contacts in the relay pictured is closed and another set is open.

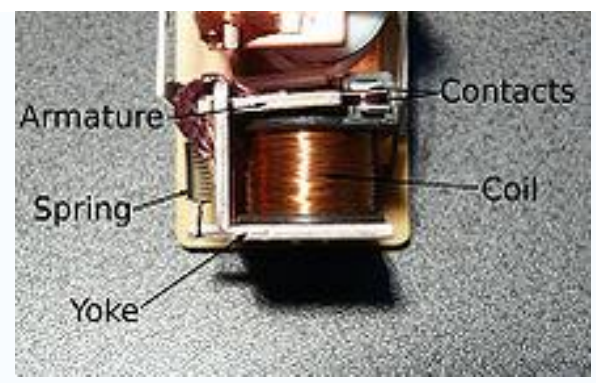

DC MOTOR: It works over a fair range of voltage. The higher the input voltage more is the RPM of the motor. The working of the gear is very interesting. It can be explained by the principle of conservation of angular momentum. The gear having smaller radius will cover more RPM than the one with larger radius. However, the larger gear will give more torque to the smaller gear than vice versa. The comparison of angular velocity between input gears in output gear gives the gear ratio. When multiple gears are connected together, conservation of energy is also followed. The direction in which the other gear rotates has been always the opposite of the gear adjacent to it.

In any DC motor, RPM and torque are inversely proportional. Hence the gear having more torque will provide a lesser RPM and converse. In a geared DC motor, the concept of pulse width modulation is applied.

In a geared motor, the gear connecting the motor and the gear head is quite small, hence it transfers more speed to the large teeth part of the gear head and makes it rotate. The larger part of the gear further turns the smaller duplex port. The small duplex port receives the torque, but not the speed of its predecessor, which it transfers to a larger part of other gear and so on. The third gear's duplex part has more teeth than others and hence it transfers more torque to the gear that is connected to the shaft.

IV.

AT COMMANDS FOR GSM MODULES 
After connecting the GSM module to a microcontroller, it can be controlled by sending instructions to it. AT commands are used to control Modems. It is used to access the information and configuration pertaining to the device and SIM card. The instruction which controls the GSM module are called AT commands. Commands are to control sending and receiving of SMS messages.

The following table lists the AT commands that are related to sending and writing of the message:

\begin{tabular}{|l|l|}
\hline AT COMMANDS & MEANING \\
\hline+ CMGS & Send message \\
\hline+ CMSS & Send message from storage \\
\hline+ CMGW & Write message in memory \\
\hline+ CMGD & Delete message \\
\hline+ CNMI & SMS alert \\
\hline+ CMMS & More message to send \\
\hline
\end{tabular}

\section{RFID INTERFACING WITH MICROCONTROLLER}

Each transponder tag contains a unique identifier which consist of antenna that is read by the RFID card reader and transmitted to the host via a simple serial interface. The card may be active or passive type. Whereas the active tag consist of battery and passive tag do not consist of a battery. It means no two tags are same. Each tag has different value. This value if read by the reader. When the RFID card reader is active and a valid RFID transponder tag is placed within range of the activated reader, the unique ID will be transmitted as a 12-byte printable ASCII string serially to the host.

The start byte and stop byte are used to easily identify that a correct string has been received from the reader (they correspond to a line feed and carriage return characters, respectively). The middle ten bytes are the actual tag's unique ID.

All communication is 8 data bits, no parity, 1 stop bit, and lest significant bit first (8N1). The baud rate is configured for $9600 \mathrm{bps}$, a standard communications speed supported by most of any microprocessor or PC and cannot be changed. The RFID card reader initiates all communications. This allows easy access to the serial data stream from any programming language that can open a COM port.

Connecting to PC: Use the supplied serial cable to connect to a PC's serial port. Use hyper terminal software which comes with Windows XP or use any other terminal software with following settings.

Data rate: 9600, Data bits: 8, Parity: None, Stop bit: 1, Floe control: None.

\section{GSM MODULE INTERFACING WITH MICROCONTROLLER}

Here the GSM is used to send the message from the shop database to the government. It is used only to send messages which consist of good detail which are sold and which are remaining, it also consists of person details who reside in a particular area. To connect a GSM with the microcontroller a special serial cable is used where the microcontroller and GSM works completely on different modes of operation. For interfacing of GSM module with microcontroller one first needs to know the GSM modem creates an interfacing environment between microcontroller and government database for exchanging messages. The GSM module can accept GSM network operator SIM card and act just like a mobile phone with its own unique phone number. To connect with GSM module to a microcontroller (PC) the RS232 is required.

\section{RESULT}

The experimental result is based on the automatic pouring of solid and liquid commodities. The pouring of these commodities is only based on timing required for the deliver of goods. When the liquid commodity is required, at first the amount must be entered when the smart card is shown, automatically it will be added to the database. The message reaches the microcontroller,it controls the pouring system through the relay drive and a DC motor. The liquid will be delivered about $100 \mathrm{ml}$ for 10 seconds. The same process is done for solid commodities; the time is fixed for particular commodities.

\section{VIII. $\quad$ FUTURE WORK}

Though this project is used to eliminate corruption of public distribution goods and irregularities of data that are entered in the register by man power, a separate database is maintained. The same system with existing components can also be used for keeping employee's record in multi branch organizations. It is possible by creating a common database for multi branches.

For supplying the goods, level sensors are used for accurate measurement of liquid and weight measurement for solid foods. By placing these sensors and weight measurement device at the end of the reservoir the quantity of goods can be measured automatically. 
IX

\section{CONCLUSION}

This experiment is used to identify the right person holding the smart card and deliver their goods in an automated way. Different database is maintained for personal details, goods sold and that are remaining in the shop and some message information. GSM is used to send message to the government database. Automatic pouring of both solid and liquid commodities make this system more efficient one. It changes the shopping environment from traditional one to sophisticated one. This creates the transparency in public distribution system as much of the work becoming automatic. With the help of this it is possible to make the public distribution system into an efficient method.

\section{REFERENCES}

[1] Rajesh C. Pingle and P. B. Burial, "Automatic rationing for public distribution system using RFID and GSM module for preventing smuggling of goods", 2011.

[2] Z. Zyonar, Karl Kammelander, Peter Jung, "evolution towards $3{ }^{\text {rd }}$ Generation Systems", 1988.

[3] Jorg Eberspacher, Hans-Joerg Vogel, Christian Bettstetter,"GSM Architecture. Protocols and Services", 2008.

[4] RFID Journal,"Wal-mart is RFID process. Changes". http://www. Intrinsic-id.com/cryptocores.htm

[5] S. Lahiri, RFID Sourcebook, USA: IBM press, 2006.

[6] http://www.Omni-id.com/pdfs/Omni-ID_Fit_200_datasheet.pdf. 